\title{
An Analysis of the Characters of Chinese Calligraphy Art Based on Mathematical Elements
}

\author{
Yuexi Wu \\ Boston University, Boston, MA, USA \\ Email: wuyuexi010608@126.com
}

How to cite this paper: $\mathrm{Wu}$, Y.X. (2020) An Analysis of the Characters of Chinese Calligraphy Art Based on Mathematical Elements. Open Journal of Applied Sciences, 10, 25-40.

https://doi.org/10.4236/ojapps.2020.102003

Received: February 3, 2020

Accepted: February 23, 2020

Published: February 26, 2020

Copyright (๑) 2020 by author(s) and Scientific Research Publishing Inc. This work is licensed under the Creative Commons Attribution International License (CC BY 4.0).

http://creativecommons.org/licenses/by/4.0/

\begin{abstract}
Mathematics is an effective way to measure or describe things objectively and accurately. It is of great significance to accurately master stroke trend, font structure and component position to improve the level of calligraphy art. This paper tries to use mathematical elements to analyze the art of calligraphy. It is concluded that through the knowledge of angle, golden section, structure and curve in mathematics, the rule of stroke trend, font structure, component position, and work shape as well as the overall layout of characters can be identified.
\end{abstract}

\section{Keywords}

Calligraphy, Mathematics, Angle, Structure, Curve

Open Access

\section{Introduction}

Chinese characters belong to the few remaining ideographic characters around the world, and they are also few characters that can be used as artworks. Chinese calligraphy is an ancient art, and its developments can be divided into several periods as follows: oracle bone inscriptions, golden inscriptions, great usurpation, minor usurpation, and official script. It is nearly in the Eastern Han dynasty and Wei and Jin dynasties that the Chinese characters were shaped by cursive script, regular script and running script which generally keep different characters in shapes and structures. As an art, the traditional Chinese calligraphy has been widely loved and studied since its formation.

The skills of calligraphy art can be roughly divided into stroke, font structure, font shape, white cloth, text layout and other types that are considered the basic elements of calligraphy art. The rule of artistic treatment of these elements is the 
skill of calligraphy art. A large number of calligraphy works are included in various calligraphy copybooks and reference books published at present. At the same time, calligraphers' professional discussions and comments on writing skills have also been involved. But there are lots of professional terms, causing most of the practitioners hard to understand and use those books. Thus, the calligraphy practitioners can only repeat their practices to build up their own experience producing better calligraphy works, who has gradually groped out the rules of calligraphy writing. This kind of practicing method is time-wasting and not efficient at all.

Karl Marx said: Science, only successfully using mathematics can reach perfection. As a basic subject, the paper thus attempts to dissect the calligraphy art from a mathematical lens, which always lays a solid foundation for scientific research. The aim of this research rests on how to demonstrate the regular skills in calligraphy with relevant mathematical elements and make these skills easier to understand, master and apply for the public, especially for calligraphy learners. Ultimately, this research is based on the relevant theories in the field of calligraphy, explores the effect of mathematical knowledge on discovering the beauty of calligraphy works, and tries to fulfill the purpose of improving the artistic level of calligraphy with mathematical knowledge. This kind of artistic analysis method on the basis of mathematical thinking is of practical significance not only in helping practitioners to master skills quickly, but also in providing new ideas for deeper analysis of the nature of calligraphy art. It also proves again that mathematics, as a fundamental discipline, plays an important role in all fields of research.

\section{Related Works}

To make the study more extensively applicable, the paper analyzes various elements of the calligraphy art, including stroke, point (formed by crossing strokes), components (made up of strokes), the different carriers of Chinese characters and the different spatial layouts of calligraphy works. It also analyzes different types of calligraphy elements and summarizes the rules based on ideas of point-to-line, line-to-surface and plane-to-space in mathematics. According to analysis of calligraphy copybooks and reading, combined with math elements like perspective, proportion, center, and the curve function, the paper employs simple graphics and measurable data to present the obscure expressions and abstract concepts relevant to Chinese calligraphy. Thus, the practitioners can rely on the simplest mathematical knowledge to quickly master the skills of calligraphy, understand the important role of mathematics in art aesthetic, and take their understanding of calligraphy art to the next level.

\section{The Progress of Research}

In the early stage of human civilization, people carved images on tortoise shells, animal bones, and these simple strokes [1], some of which even bent so signifi- 
cantly that people could hardly identify even now, have ever since undergone a fairly long period of developments. These images form the earliest strokes of Chinese characters that we can see nowadays. The basic strokes of Chinese characters are mostly geometric curves in mathematics [2]. Based on relevant theories in mathematics, the academia generally holds that the bending position of Chinese characters is based on some special angles such as $30^{\circ}, 45^{\circ}, 60^{\circ}, 90^{\circ}$, $120^{\circ}$, and $150^{\circ}$, and the curve position of Chinese characters are accordingly based on arc lines. The flexible use of those angles further contributes to the formation of the general structure of Chinese characters.

\subsection{Strokes and Angles}

\subsubsection{Horizontal "Flat" and Obtuse Angle}

Horizontal is the main component of cuneiform and the most basic stroke in Chinese calligraphy, Figure 1 shows the trace of pen movement. When the characters are written horizontally, their strokes should be made as smooth as they can be, the end of the strokes should be like a horse's head with the reins tightened [3]. In this paper, the horizontal is viewed as a straight angle of $180^{\circ}$, in order to avoid the edge of the pen shake. At the same time, when the pen used to write the relevant characters is held, it needs to be adjusted to form a $150^{\circ}$ angle, and the short edge on the right side of the angle should then be adopted in order to create a supporting effect and make the strokes turn out to be more stable, because symmetry and fullness are the most basic aesthetic requirements [4], as shown in Figure 2.

\subsubsection{The Turning and Included Angle of Horizontal and Vertical Paintings}

With the progress of society, there have been increasingly rich contents to be recorded by Chinese characters. This demand has greatly boosted the growth of both the types and numbers of Chinese characters. The strokes that make up

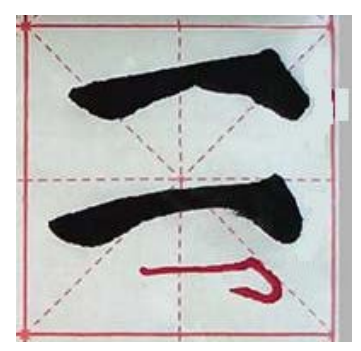

Figure 1. The strokes track of horizontal line.

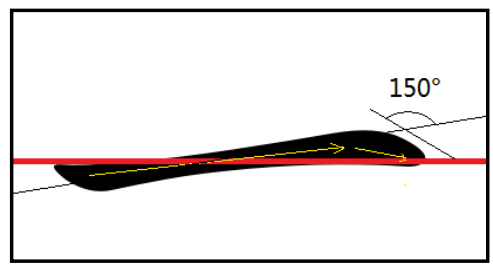

Figure 2. The angle of the stroke tail. 
Chinese characters have thus also become more complex. In order to write Chinese characters better, some softer and finer brushes, as well as flat animal skins, bamboo slips and silk cloth started to emerge. This has further provided the conditions for more angle to derive accordingly, making a number of angles produced even in one single stroke of each character. As Figure 3 shows below, the horizontal line and vertical line of the upper right part of the Chinese character “国 (means country or nation)” together form an angle of $90^{\circ}$ internally and an angle of $150^{\circ}$ externally. As Figure 4 shows as follows, the starting stroke and middle stroke of the upper right part of the Chinese character “仍 (means still)" form an angle of $60^{\circ}$ while the middle stroke and the horizontal line form an angle of $75^{\circ}$, tip first right up and then left down, not horizontal or vertical [5]. Those angles make the font look upper wide and lower tight, one that is generally recognized to be written squarely and made beautifully done.

\subsubsection{Circles and Arcs in Strokes}

The appearance of the curve is a significant improvement of the art of calligraphy. The Greek Pythagorean schools believe that the circle is the most beautiful geometric figure. Take Figure 5 and Figure 6 for example, which shows the

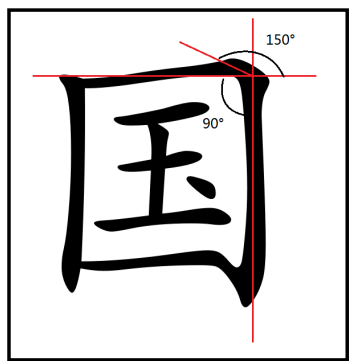

Figure 3. The angle of the outline for the character.

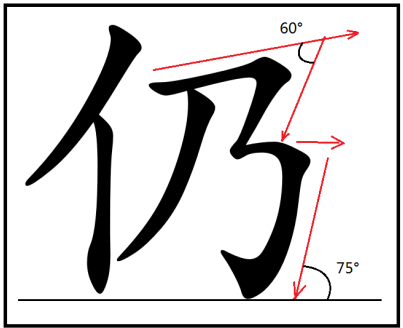

Figure 4. The angle of the outline for the character.

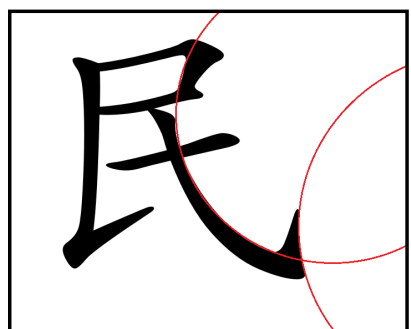

Figure 5. The track in the stroke of circle or arc. 


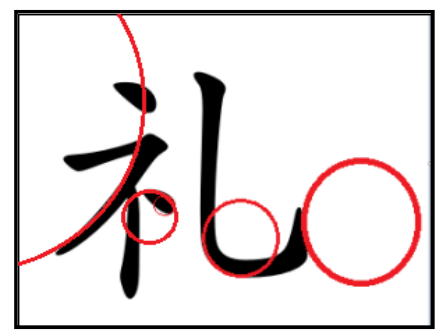

Figure 6. The track of multiple circles in the stroke.

Chinese character “民 (means people)” and “礼 (means rites or ritual)” respectively, the beauty of harmony between circle and arc from the strokes of the zero curve can be easily seen, with the greater radian and bend of the stroke lines.

\subsection{Font Structure and Golden Ratio}

With the appearance of ideographic characters, the forms of Chinese characters cast off the shackles of the image of natural things. Such changes, on the one hand enriched the connotation of the texts, while on the other hand, they also improved the ability of expression. Through generations of human's exploration, the golden section has been identified effective in terms of making the Chinese characters seem more beautifully written, and thus this concept, widely used in making potteries look more proportionate or optimizing the structure of the buildings we live in, has been naturally applied to make the Chinese characters look as genuine as the original Characters. For the convenience of analysis, this paper calculated the different golden sections of Chinese characters including 0.618 as 0.6 and 0.382 as 0.4 , and explored the rules behind each golden section based on the ratios such as 3:2 or 2:3.

\subsubsection{Golden Section in Font Contour}

By comparing Figure 7 with Figure 8, it can be seen that the outline of most Chinese characters is just like Da Vinci's man "Vitruvius", like a standing man with a frame close to the golden ratio. Study on Calligraphy by Qi Gong is the most representative work. It is described in many languages and can be simply summarized as follows.

\subsubsection{The Golden Section in the Strokes}

In Figure 9, the connecting point of the stroke falls exactly on the golden section point of the center line. On the whole, the stroke at the golden section point can make the whole glyph present the basic outline of an equilateral triangle, which looks more stable and beautiful. There are two golden section points in Figure 10. It can be seen from the schematic diagram that the two intersections are 0.6 and 0.4 of the whole stroke respectively. Although there is a slight change in the whole with the standard of golden section.

Even if the strokes belong to the same category, there are also different lengths in writing which basically meet the golden ratio. For example, the horizontal line in Figure 11 has an upper and lower ratio of 3:2. The ratio of the same stroke in 


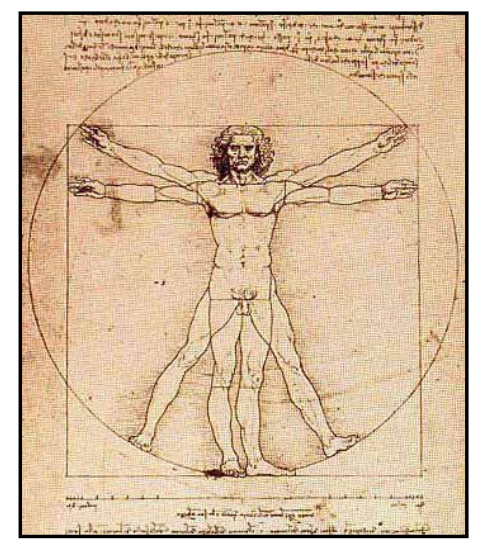

Figure 7. The golden section of human body.

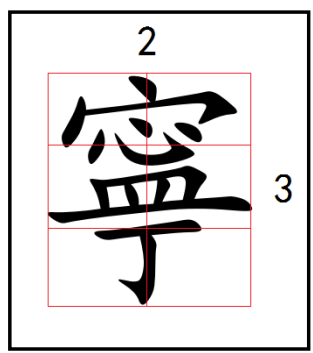

Figure 8. The golden section of the font.

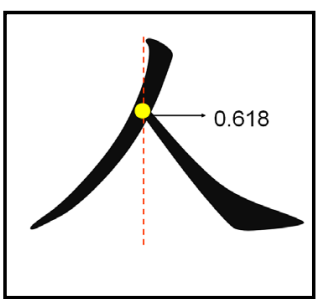

Figure 9. The golden section formed by the connecting point.

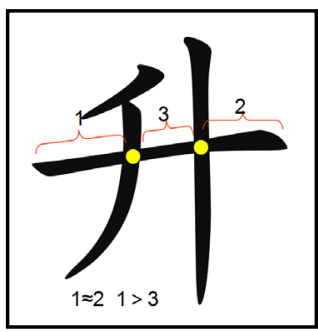

Figure 10. The golden section formed by the multiple connecting point.

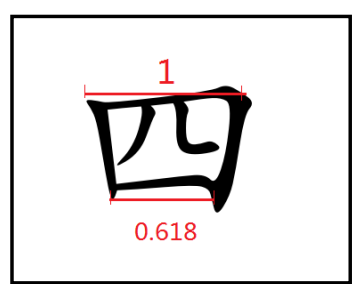

Figure 11. The golden section of the same category. 
Figure 12 is also 3:2. The most obvious example is Figure 13. Many posts mention that "the middle stroke should be a little shorter", but there is little specific description of how short it is. Then, according to the standard of golden section, a ratio of 1:0.61 formed with the last stroke presents the best effects of visual beauty.

\subsection{The Changes in Calligraphy Form and Center Position}

The tools of writing have changed from simple such as stone walls, clay tablets and clay pots, to rich carriers such as silk cloth, silk and paper. With more and more sufficient space provided for the foundation of the writing of calligraphy art, the most obvious changes go to calligraphy forms. The changes in the calligraphy forms are usually realized by the displacement of the center which results in the improvement of the visual effect [6].

\subsubsection{The Changes in the Center of the Glyph}

There are fewer strokes in Figure 14 and Figure 15. Hence, the paper just pays attention to the compact structure and stable center of gravity when the characters (“九一nine”, “米—rice”) are written. Thus, the character (“九一nine”) in Figure 14 moves the center of the glyph A to point B by raising the strokes from

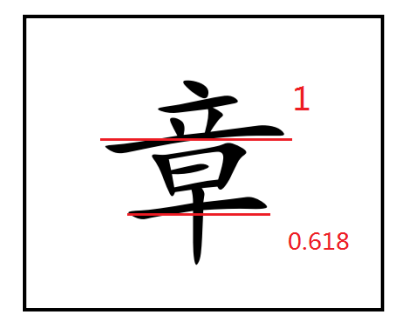

Figure 12. The golden section of different components.

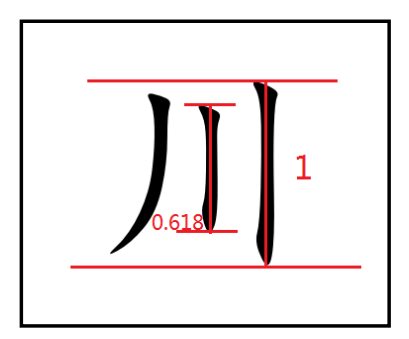

Figure 13. The different proportion of the same stroke.

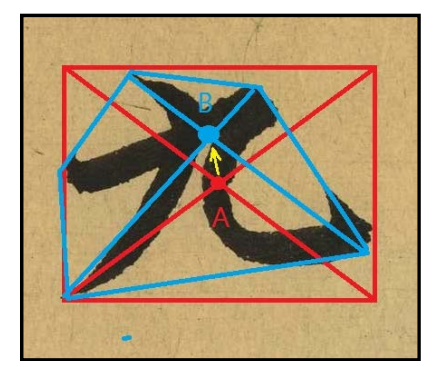

Figure 14. Moving up of the center of the Glyph. 


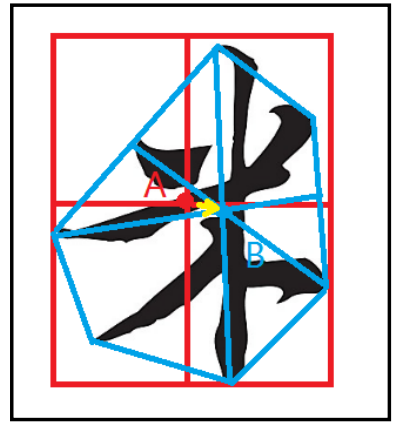

Figure 15. Moving right of the center of the Glyph.

left to right, forming A straight image, while Figure 15 shows that in the character (“米—rice"), with its center position moved to the right, the center symmetry of the glyph is broken, forming a more flexible glyph and avoiding the appearance of a rigid image in terms of the entire character.

\subsubsection{Center between Components}

The central position of Chinese characters plays a vital role in overall beauty of the character form. Generally, the center of Chinese characters should be determined by the main component. As Figure 16 shows, the main component is the right half. Therefore, the font shape should be adjusted through stroke changes, so that the center point $\mathrm{A}$ of the two components should be shifted to the right half of the component. Similarly, the main component of Figure 17 is the left half. Through the process of stroke extension of the right half, the center point $\mathrm{A}$ is shifted to the left half of the component.

\subsubsection{The Center of Stroke Formation}

Take Figure 18 and Figure 19 for example, when there are more than one stroke of a character, there will be a connection between the strokes which makes the structure of the character look more compact. In Figure 18, the intersection point of the bottom stroke trace line is the center of the font, diffracting a relatively stable triangle that forms a regular font shape. The bottom stroke of the character “照” (means shine) in Figure 19 has a clearly aligned layout drawn from a horizontal position of the same height to the left, which is very neat.

\subsection{Calligraphy Cloth White with Geometric Figures}

With the maturity of the writing skills of Chinese characters, more and more people regard calligraphy as an art rather than simply as a tool. The recording function of calligraphy has been gradually weakened, and the function as a form of art becomes more prominent [7]. Therefore, calligraphy began to appear in daily life as a work of art. In order to better showcase the beauty of the art of calligraphy, people used geometric figures to design the shape and blank, and introduced the concept of "counting white when black", which enriched the aesthetic elements of the art of calligraphy again, searching for the law of aesthetics outside the characters [8]. 


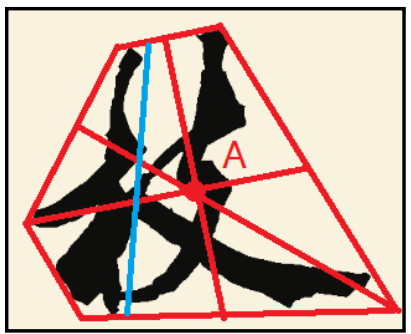

Figure 16. Moving right of the center.

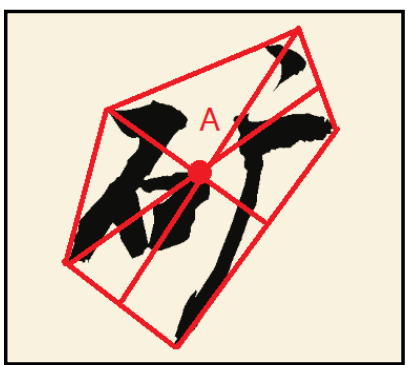

Figure 17. Moving left of the center.

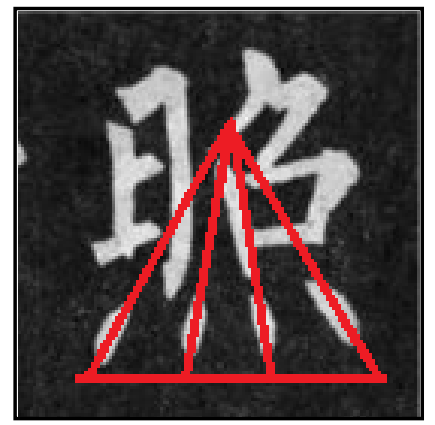

Figure 18. The center of the inside font.

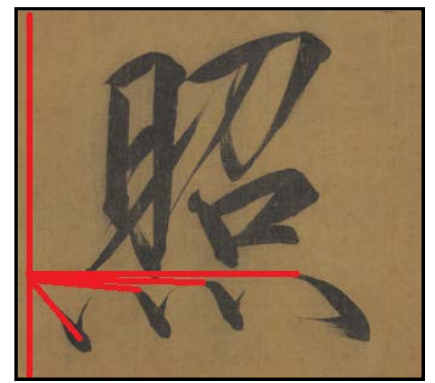

Figure 19. The center of the outside font.

\subsubsection{Rectangular Calligraphy Works}

Rectangular is one of the commonest forms of calligraphy. Figure 20 below is a horizontal rectangular calligraphy work with $1 / 3$ the width of the overall length, which can be written in single lines of large characters or several lines of small characters. This form can be traced back to the ancient scrolls or bamboo slips. Figure 21 and Figure 22 are vertical rectangular calligraphic works with a 3:1 ratio of length to width, just like a single page in a book. 


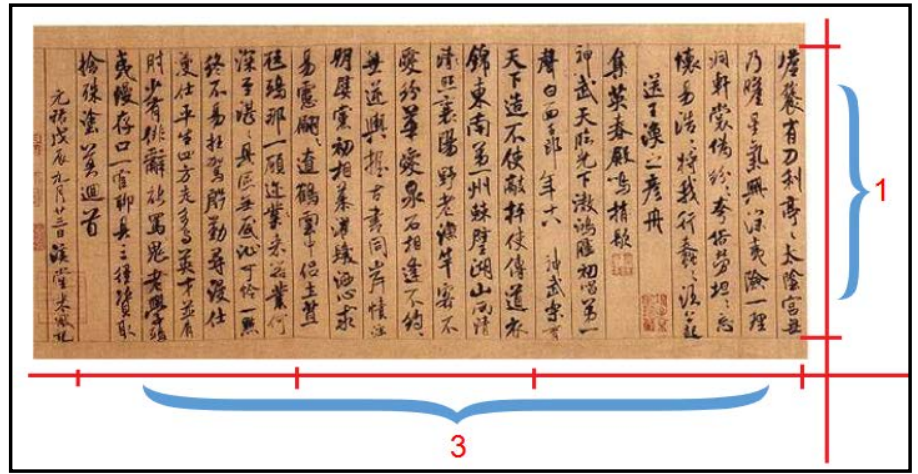

Figure 20. The proportion of horizontal calligraphy works.

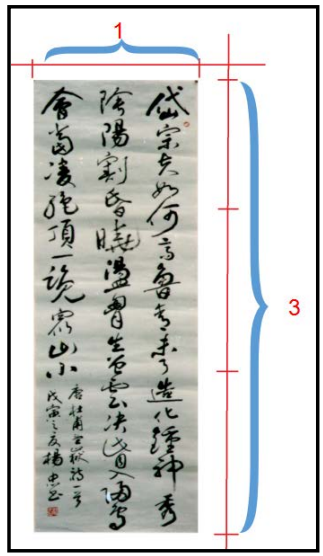

Figure 21. The proportion of vertiacl calligraphy works.

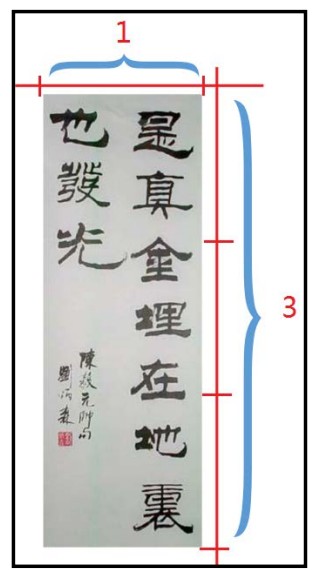

Figure 22. The proportion of vertical calligraphy works.

\subsubsection{Round Calligraphy Works}

In artistic aesthetics, people have a special preference for the round shape that is full of harmonious beauty, and the same is true in the art of calligraphy. A calligraphy work with a circular outline, usually mounted in a picture frame and hung indoors for appreciation. When writing, people should notice the distance of the arc of big circle of outer circle and the characters to achieve equalization. Take Figure 23 for example, circle $\mathrm{A}$ is the outer frame, and B, D, F and $\mathrm{H}$ are 


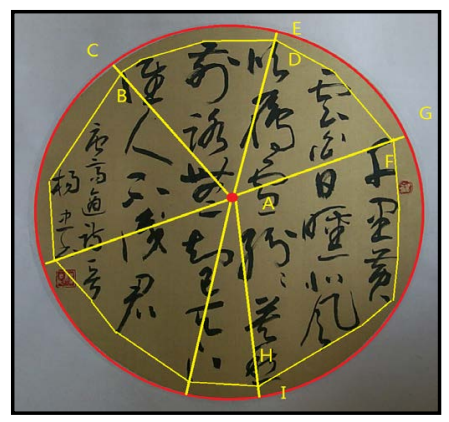

Figure 23. The radius and center of the circle of circle calligraphy works.

the outermost points of each character in the body of the calligraphy. People use the radius that passes through these points as the mid perpendicular to make a tangent line of a circle. It can be seen that the lengths of BC, DE, FG and HI are roughly the same which reflect "juzheng" (following the right way) and completeness in ancient Chinese philosophy [9]. The fan in Figure 24 is a calligraphy work with a certain curve and unique shape that can be regarded as a fan in a geometric figure, or a space formed by the superposition of two circles. Compared with the center of the mirror, the application of mathematical knowledge of the fan is more complex. It is a late mounting process.

\subsection{Calligraphy Aesthetics and Function Curve}

Calligraphy is an important form for ancient Chinese literati to show their individuality and express their aspirations and interests. It has been said that "the style of a man's characters shows who he or she is." Therefore, calligraphy works are greatly influenced by social environment and the author's personal experience. Take Figure 25 for example, the work is named Orchid Pavilion, which is known as the "Zenith of cursive script", and it was created in Wei-Jin period [10]. The political environment back then was full of darkness and cruelty so that a large number of scholars were forced to give up being officials and instead turn to study the metaphysics, astronomy, science and technology. Those factors exerted a subtle influence on the calligraphy art at that time. The style of calligraphy also presents flexibility, but not the characteristics of the bound. Especially in mathematics, the research achievements by mathematicians Liu Hui and $\mathrm{Zu}$ Chongzhi have also provided a new form of mathematical expression for art of calligraphy, this kind of regular fluctuation is easy to cause the aesthetic experience and imagination of the viewers [11], thus in this paper the function curve has been used to analyze the calligraphy.

\subsubsection{The Wave Changes in Columns}

As shown in Figure 26, take the fifth columns for example, which mainly illustrate the wave changes in columns, the axis of the $1^{\text {st }}$ and the $7^{\text {th }}$ character is to right, and the axis of the $4^{\text {th }}$ the $10^{\text {th }}$ character is to left. The axis of the last character is to right again. Also, the axis of each character not only deviates from left to right, but also changes in tilt direction. 


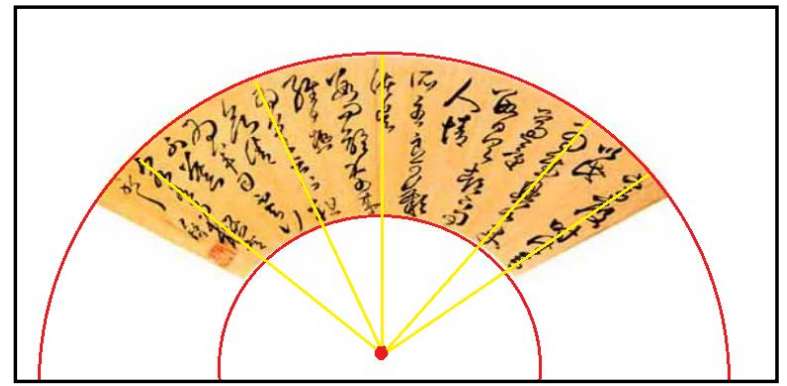

Figure 24. The radius and center of the circle of fan calligraphy works.

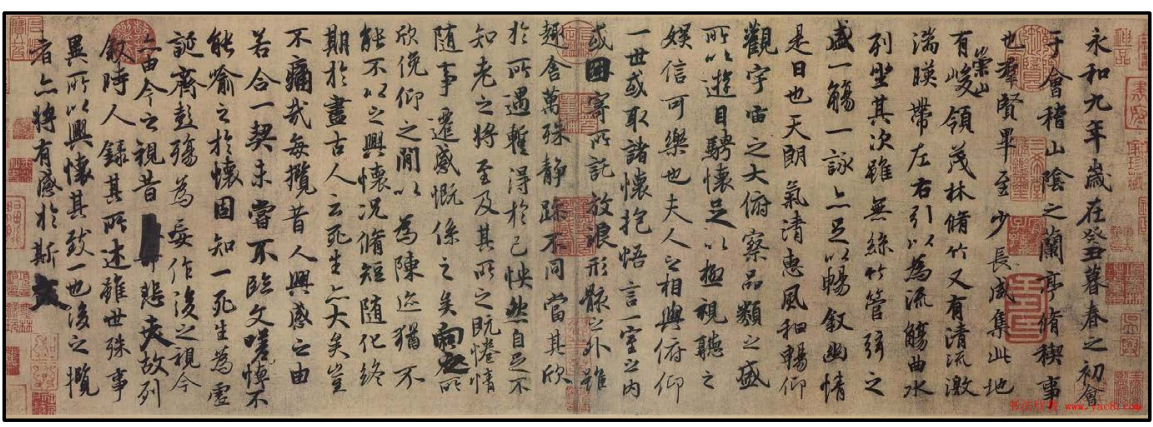

Figure 25. Orchid Pavilion.

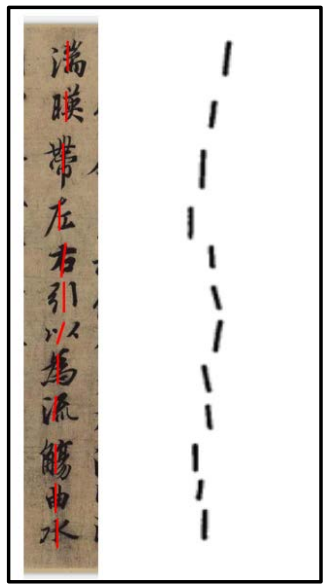

Figure 26. The changes of the position and direction for the middle line.

The axis of the first character obviously tilts to right. The axis of the first character tilts to left. The axis of the seventh character tilts to right again while that of the ninth character tilts to left again. In this paper, a sine curve is used to symbolically describe the size of a font. Take the ninth column in Figure 27 for example, it can be seen that the first character is the peak because of its bigger font, the third character is the valley due to its smaller font, the sixth character is the peak, and the eighth character is the valley. By that analogy, the paper concludes the function curve shown in Figure 28.

\subsubsection{The Wave Changes of Interval Density}

The study of the character density involves analyzing the different locations of 


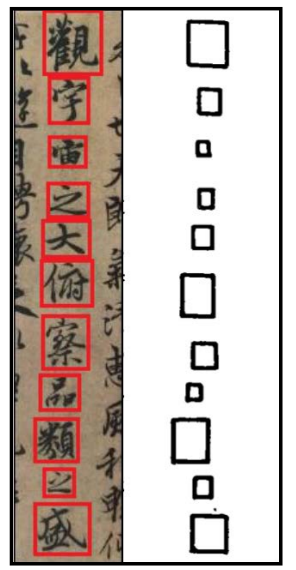

Figure 27. The changes of the font size.

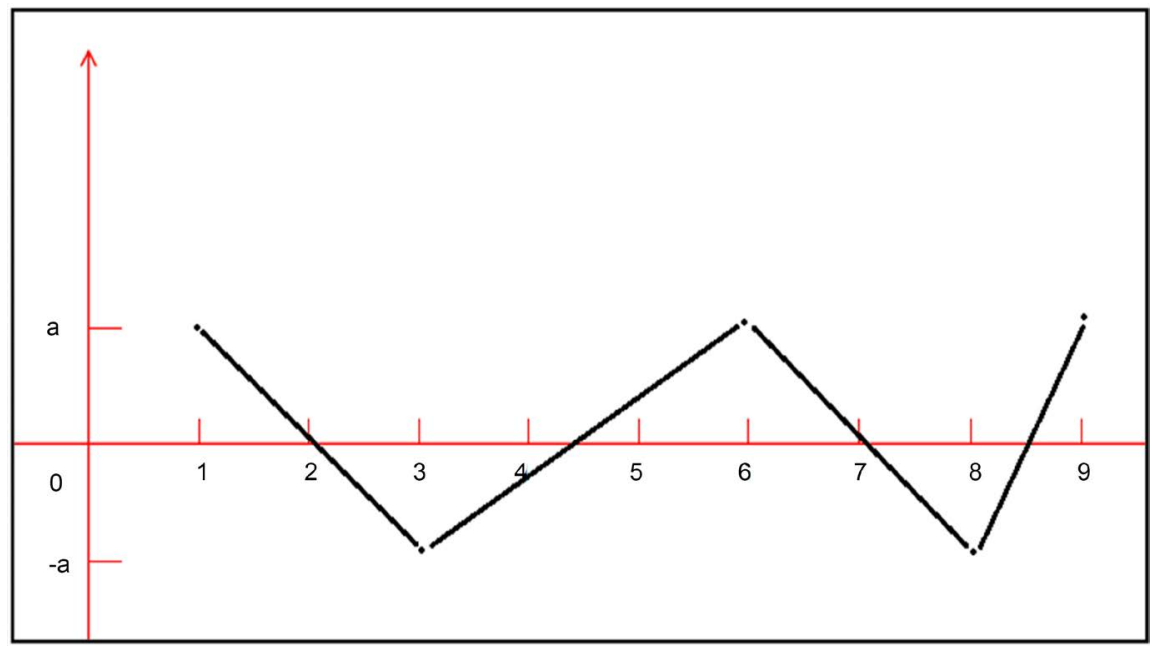

Figure 28. The function diagram of the changes for the font size.

the character. In order to facilitate this analysis, the paper sets up a coordinate system on the whole picture. The upper right corner of the work is for the origin, $X(m, n) . X$ refers to a Chinese character in the work. $M$ and $n$ respectively are two positive integers. $M$ refers to the ordinal number of the column, and $n$ refers to the ordinal number of the character. For example, the paper uses $A(1,1)$ to represent the first character in the first column, and uses $B(7,9)$ to represent the ninth character in the seventh column thus people can quickly and accurately search the character in the work with this kind of coordinate method, and the exact position can thus be determined based on the coordinate.

Take the $6^{\text {th }}$ column in Figure 29 for example, the distance from $A(6,4)$ to $\mathrm{B}(6,3)$ and $\mathrm{C}(6,5)$ looks closer. The distance from $\mathrm{D}(6,6)$ to $\mathrm{C}(6,5)$ and $\mathrm{E}(6,7)$ looks farther. The distance from $\mathrm{F}(6,8)$ to $\mathrm{E}(6,7)$ and $\mathrm{G}(6,9)$ looks closer. The distance from $\mathrm{H}(6,10)$ to $\mathrm{G}(6,9)$ and $\mathrm{I}(6,11)$ looks farther. If closer distance symbolizes the peak and farther distance symbolizes the valley, then it can be clearly seen that this kind of periodical change, like sine curve, is described by the specific function as Figure 30. 


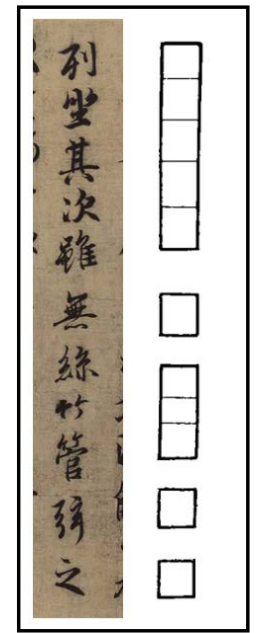

Figure 29. The changes of the space between characters.

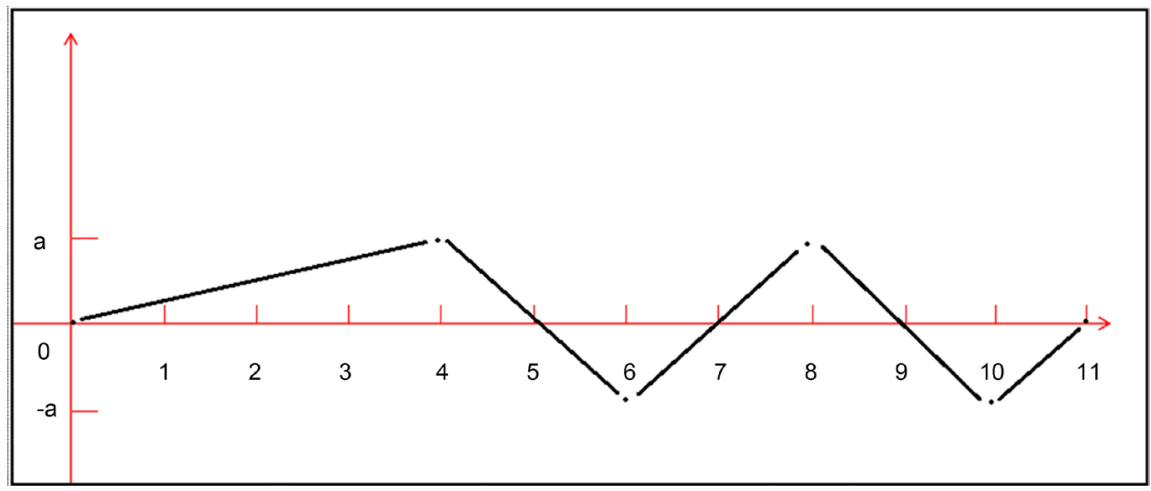

Figure 30. The function diagram of the changes of the space between characters.

\subsubsection{The Wave Changes of Stroke Weight}

Similar to the periodical changes of different density, there is a rule in the stroke weight of each line in Orchid Pacillion. Take the $22^{\text {nd }}$ column in Figure 31 for example, $\mathrm{A}(22,4)$ is written thickly and looks heavier. This is the peak. $\mathrm{B}(22,5)$, the strokes are thinner and the font is small. This is the valley. $C(22,7)$ and $\mathrm{D}(22,10)$ are written thickly again. They are both the peaks. $\mathrm{E}(22,12)$, the font is small. This is the valley as the end of the column. The function curve is shown as Figure 32.

\section{Conclusion and Future Work}

\subsection{Conclusion}

Mathematics accurately expresses the rules and skills of things, while the skills and rules of Chinese characters and calligraphy can also be described by mathematical concepts. With simple mathematical knowledge, this paper analyzes some representative Chinese characters, and illustrates the skills of calligraphy art. It verifies that the mathematical knowledge explains the rules and skills in calligraphy better. Besides, it allows the beginners to quickly understand and apply the rules to improve the level of calligraphy. 


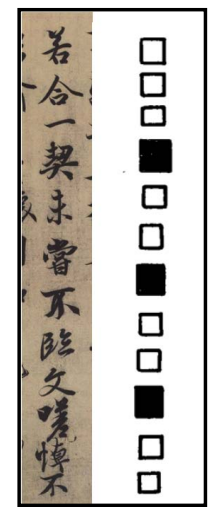

Figure 31 . The changes of lightly or thickly written.

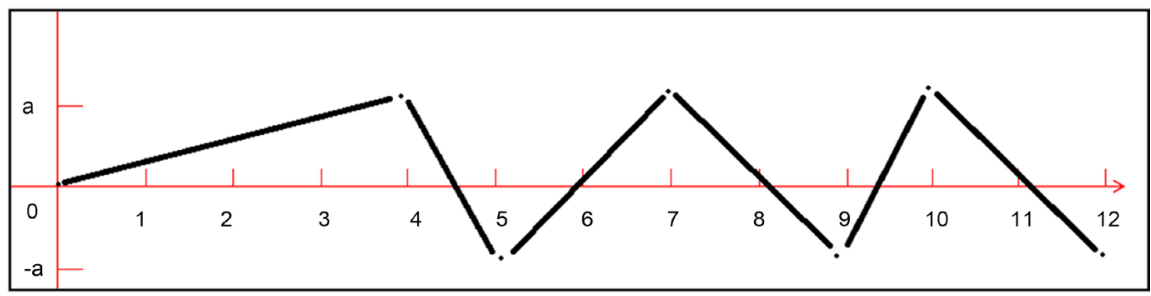

Figure 32. The function diagram of the changes of lightly or thickly written strokes.

\subsection{Future Work}

Chinese calligraphy is a special form of Chinese characters. It is an art that comes from nature and has been continuously processed and sublimated by countless Chinese people. Nowadays, more and more people like and practice calligraphy. However, there are still some things needing to be further improved:

1) Select more analysis objects and extract more general skills and rules.

2) Establish a better and accurate coordinate system to make mathematical elements such as angles and functions more concrete.

3) Further explore the representation of mathematics in other calligraphy elements such as seal, signature and mounting position.

The paper hopes to further research and analyze the above content and other related fields to make the major findings in this paper understood more accurately and thoroughly, and ultimately, to make the calligraphy art gain more traction around the world in a way that people can learn more about this art and apply skills they acquire to constantly make progress in this art.

\section{Conflicts of Interest}

The author declares no conflicts of interest regarding the publication of this paper.

\section{References}

[1] Wang, H. (2011) The Originating Time of Chinese Writing System. Journal of the Shaanxi Normal University (Philosophy and Social Sciences Edition), No. 3, 5-23.

[2] Liao, Y.X. (1998) Study on Mathematics and Calligraphy. Tian Fu Mathematics, 10, 
15.

[3] Zhou, R.C. and Zhou, L.L. (2015) Eight Fundamental Strokes in Character Yong (永): Handouts on the Art of Calligraphy. Second Edition, Guangxi Normal University Press, Guilin.

[4] Qiu, Z.Z. (2012) Calligraphy and Guidelines. Jiangxi Arts Press, Nanchang.

[5] Tian, Y.Z., Hua, X. and Wan, J. (2015) A Primer on Regular Script by Ouyang Xun: The Inscription of Jiu Cheng Palace Spring. Hunan Art Press, Changsha.

[6] Zhu, M.S. (2012) College Calligraphy. Fudan University Press, Shanghai.

[7] Fei, X.W. (2008) The Method of Study Calligraphy. Zhonghua Book Company, Beijing.

[8] Jiang, X. (2014) The Beauty of Chinese Calligraphy. Guangxi Normal University Press, Guilin.

[9] Sun, X.Y. (2010) The Method of Calligraphy. Phoenix Publishing \& Media, Jiangsu Arts Press, Nanjing.

[10] Editorial Department of the Commercial Press (2012) Orchid Pavilion: The Work of Great Calligrapher Classic Required New Reading. World Book Publishing Company, Beijing.

[11] The Palace Museum (2009) The Intensive Teaching of Orchid Pavilion by Wang Xizhi (Vertical Row). The Forbidden City Press, Beijing. 